\title{
Systematic Endoscopic Approach for Diagnosing Gastric Subepithelial Tumors
}

\author{
Gwang Ha Kim \\ Department of Internal Medicine, Pusan National University College of Medicine and Biomedical Research Institute, Pusan National \\ University Hospital, Busan, Korea
}

\author{
Article Info \\ Received September 23, 2020 \\ Revised December 28, 2020 \\ Accepted January 5, 2021 \\ Published online March 15, 2021 \\ Corresponding Author \\ Gwang Ha Kim \\ ORCID https://orcid.org/0000-0001-9721-5734 \\ E-mail doc0224@pusan.ac.kr
}

\begin{abstract}
Subepithelial tumors (SETs) are commonly encountered during upper gastrointestinal endoscopy, especially during national gastric cancer screening programs in Korea. Although the majority of SETs are benign, endoscopists harbor concerns regarding whether a SET is benign or malignant because the diagnosis cannot be established on the basis of routine endoscopic biopsy findings. The differential diagnosis of SETs is important, beginning with meticulous endoscopic examination, including the evaluation of the location, macroscopic shape, color, surface characteristics, mobility, consistency, and size of the tumors. The yield of endoscopic biopsy increases with the use of the bite-on-bite technique for SETs without the rolling or tenting sign, with large openings, and with erosion or ulceration. In this review, a systematic approach for the diagnosis of gastric SETs during conventional endoscopy is introduced. (Gut Liver 2022;16:19-27)
\end{abstract}

Key Words: Endoscopy; Stomach; Subepithelial tumor

\section{INTRODUCTION}

Subepithelial tumors (SETs) in the gastrointestinal tract may arise from any layer between the deep mucosa and the serosa, depending on the histopathologic type. SETs are mostly asymptomatic lesions covered by the normal mucosa, which are commonly incidentally encountered during endoscopic or radiologic examinations, especially during national gastric cancer screening programs in Korea and Japan. The precise incidence of gastric SETs is not known. According to a recent multicenter study by the Korean Research Group for Endoscopy Ultrasound, the prevalence of SETs detected during screening esophagogastroduodenoscopy was $1.9 \%$ in Korea, and they were commonly detected in the stomach $(64.1 \%) .{ }^{1}$

The differential diagnosis of SETs is important, beginning with meticulous endoscopic examination. The size, shape, color, mobility, and consistency of the tumors and the presence of erosion or ulceration in the overlying mucosa should be observed. In general, SETs present with normal-appearing mucosa; the presence of erythema or ulceration is associated with the risk of an increase in the size of the SETs. ${ }^{2}$ Several signs that can be confirmed by manipulation of SETs using biopsy forceps, including the rolling sign, pillow sign, or tenting sign, can be useful during the differential diagnosis.

The majority of SETs are benign at the time of diagnosis, and $<15 \%$ of the SETs are found to be malignant. ${ }^{3}$ A study that evaluated the natural history of 954 SETs in the upper gastrointestinal tract reported that only $3.6 \%$ showed at least $25 \%$ increase in diameter during the mean follow-up period of 47.3 months (range, 6 to 118 months). ${ }^{2}$ Another study that included 989 gastric SETs in 948 patients showed that only $8.5 \%$ tumors showed significant changes in size, echogenicity, and/or morphology in the median period of 24 months (range, 3 to 123 months). ${ }^{4}$ However, endoscopists and patients are concerned regarding whether an SET is benign or malignant because the diagnosis cannot be established on the basis of routine endoscopic biopsy findings. Sometimes, advanced diagnostic modalities, such as endoscopic ultrasonography (EUS) and more invasive procedures (EUS-guided fine-needle aspiration/biopsy or mucosal cutting biopsy), are required for confirming the diagnosis. ${ }^{5-9}$ However, many SETs can be diagnosed via a 
systematic endoscopic approach alone. Considering that advanced diagnostic modalities are not available to all endoscopists, endoscopists should focus more on the differential diagnosis of SETs based on the endoscopic findings. This review aimed to introduce a systematic approach for diagnosing gastric SETs during conventional endoscopy based on my experience.

\section{FEATURES TO BE FOCUSED ON DURING CONVENTIONAL ENDOSCOPY}

When an SET is observed in the stomach, most endoscopists are interested in the detection of the tumor itself and then recommend further evaluation, such as EUS. However, if the endoscopists pay more attention to the SET itself, it is possible to predict the histopathologic diagnosis without conducting further evaluation to some degree. Therefore, more detailed endoscopic information, such as the location, macroscopic shape, color, surface characteristics, movability, consistency, and size of the SETs, should be evaluated during endoscopy. The endoscopic features of SETs according to histopathology are summarized in Table 1.

\section{Location}

Although the concept may not hold true for all SETs, the predilection sites for the different types of SETs depended on the histopathology of the tumor (Fig. 1). Gastrointesti-

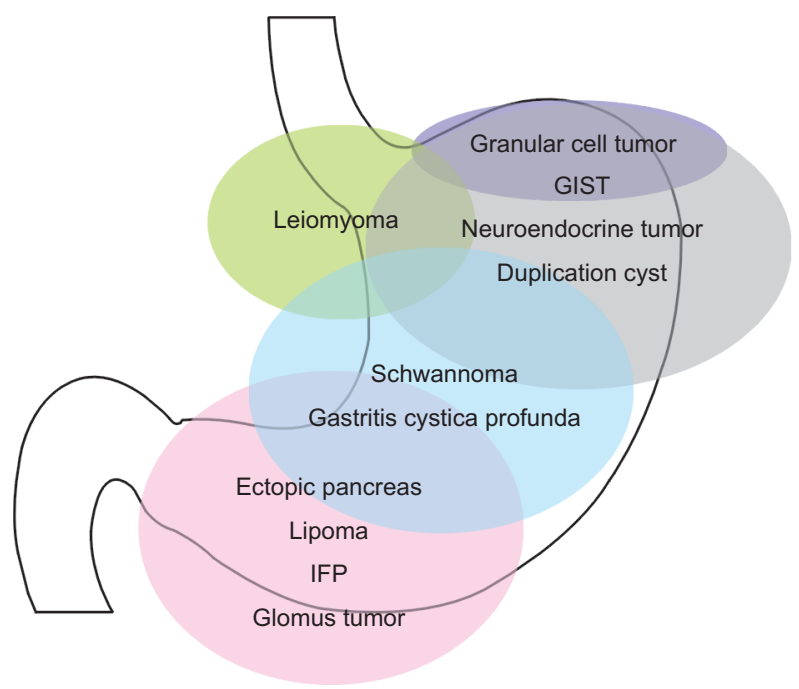

Fig. 1. Location of gastric subepithelial tumors according to the histopathology.

GIST, gastrointestinal stromal tumor; IFP, inflammatory fibroid polyp.

Table 1. Endoscopic Features of Gastric Subepithelial Tumors According to Histopathology

\begin{tabular}{|c|c|c|c|c|c|c|c|}
\hline Feature & Location & $\begin{array}{l}\text { Macroscopic } \\
\text { shape* }\end{array}$ & Color & Surface & Movability & Consistency & Other clues \\
\hline Leiomyoma & $\begin{array}{l}\text { Cardia, } \\
\quad \text { upper body }\end{array}$ & Y-I, Y-II & Normal & Smooth & $\begin{array}{l}\text { Movable/ } \\
\text { Not movable }\end{array}$ & Hard & $\begin{array}{l}\text { Middle-aged } \\
\text { women }\end{array}$ \\
\hline Varices & $\begin{array}{l}\text { Cardia, } \\
\text { fundus }\end{array}$ & Tortuous & Bluish & Smooth & Not movable & Soft & $\begin{array}{l}\text { Patients with } \\
\text { portal } \\
\text { hypertension }\end{array}$ \\
\hline Granular cell tumor & Fundus & Y-II & Yellowish & Smooth & Not movable & Hard & \\
\hline $\begin{array}{l}\text { Gastrointestinal } \\
\text { stromal tumor }\end{array}$ & $\begin{array}{l}\text { Fundus, } \\
\text { upper body }\end{array}$ & Y-I, Y-II & Normal & $\begin{array}{l}\text { Smooth } \\
\text { Sometimes erosion, } \\
\quad \text { ulceration }\end{array}$ & $\begin{array}{l}\text { Movable/ } \\
\text { Not movable }\end{array}$ & Hard & Old people \\
\hline $\begin{array}{l}\text { Neuroendocrine } \\
\text { tumor }\end{array}$ & $\begin{array}{l}\text { Fundus, } \\
\text { upper body }\end{array}$ & Y-II & Normal & Erosion & Not movable & Hard & \\
\hline Duplication cyst & $\begin{array}{l}\text { Fundus, } \\
\text { upper body }\end{array}$ & Y-I, Y-II & Normal & Smooth & Not movable & Soft & \\
\hline Schwannoma & Body & Y-I, Y-II & Normal & Smooth & Not movable & Hard & $\begin{array}{l}\text { Middle-aged } \\
\text { women }\end{array}$ \\
\hline $\begin{array}{l}\text { Gastritis cystica } \\
\text { profunda }\end{array}$ & Body & $Y-I$ & Translucent & $\begin{array}{l}\text { Smooth } \\
\text { Sometimes opening }\end{array}$ & Not movable & Soft & \\
\hline Lymphoma & Body & Y-I, Y-II & Normal & Erosion & Not movable & Hard & \\
\hline $\begin{array}{l}\text { Inflammatory } \\
\text { fibroid polyp }\end{array}$ & Antrum & $Y-I I, Y-I I I$ & Normal & Erosion & Not movable & Hard & \\
\hline Lipoma & Antrum & Y-I, Y-II & Yellowish & Smooth & Movable & Soft & \\
\hline Glomus tumor & Antrum & Y-I, Y-II & Normal & Smooth & Not movable & Hard & \\
\hline Ectopic pancreas & Antrum & $Y-1$ & Normal & Umbilication, opening & Not movable & Hard & Young people \\
\hline SET-like carcinoma & Any site & Y-I, Y-II & Normal & Erosion, ulceration & Not movable & Hard & \\
\hline Metastatic cancer & Fundus, body & Y-I, Y-II & Normal & Erosion, ulceration & Not movable & Hard & \\
\hline
\end{tabular}

SET, subepithelial tumor.

*According to the Yamada classification. ${ }^{16}$ 
nal stromal tumors (GISTs) are most commonly located in the fundus and body; leiomyomas are usually detected in the cardia and upper body and schwannomas are detected in the middle third of the stomach. ${ }^{10,11}$ SETs commonly detected in the antrum include ectopic pancreas, lipomas, inflammatory fibroid tumors (IFPs), and glomus tumors. ${ }^{12-15}$ Therefore, the endoscopists can narrow the spectrum for the diagnosis of SETs based on their location.

\section{Macroscopic shape}

The macroscopic shape of SETs can be described using the Yamada classification (Fig. 2) ${ }^{16,17}$ When an SET has a Y-I (elevation with a smooth baseline without a clear boundary) or Y-II (elevation with a boundary at the base but no notch) morphology, the tumor usually originates from the deep submucosal or muscularis propria layer (e.g., GISTs, leiomyomas, and schwannomas). In contrast, when an SET has a Y-III (elevation with a clearly notched base but no peduncle) or Y-IV morphology (pedunculated elevation), the tumor mainly originates from the deep mucosal or superficial submucosal layer (e.g., IFPs or granular cell tumors). However, almost all SETs have a Y-I or Y-II morphology, and their macroscopic shape varies according to the size and growth patterns.

\section{Color}

Almost all SETs present with a color similar to that of the surrounding normal mucosa (Fig. 3A). However, several SETs are tinged with a characteristic color. When an SET is yellowish in color, the tumor can be diagnosed as a lipoma or granular cell tumor (Fig. 3B). ${ }^{13,18}$ When it is bluish in color, the tumor is a vascular lesion, such as a varix or hemangioma (Fig. 3C). ${ }^{19}$ When an SET has a clear liquid component, such as that noted in gastritis cystica profunda or lymphangioma, its color is translucent (Fig. 3D).

\section{Surface characteristics}

As SETs are coved by the normal mucosa, almost all SETs present with smooth surface (Fig. 4A). However, several SETs sometimes present with an opening, umbilication, central dimpling, erosion, or ulceration. When an SET has a definite opening, umbilication, and/or central dimpling, the tumor can be easily diagnosed as ectopic pancreas (Fig. 4B). The detection of microscopic opening
Type I

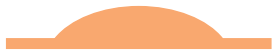

Elevation with a smooth baseline without a clear boundary

Type II

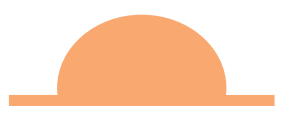

Elevation with a boundary at the base but no notch

Type III

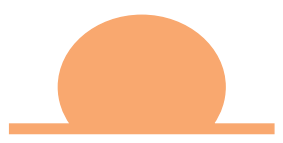

Elevation with a clearly notched base but no peduncle

Type IV

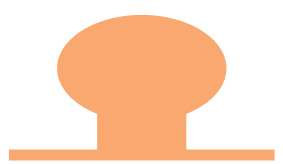

Pedunculated elevation
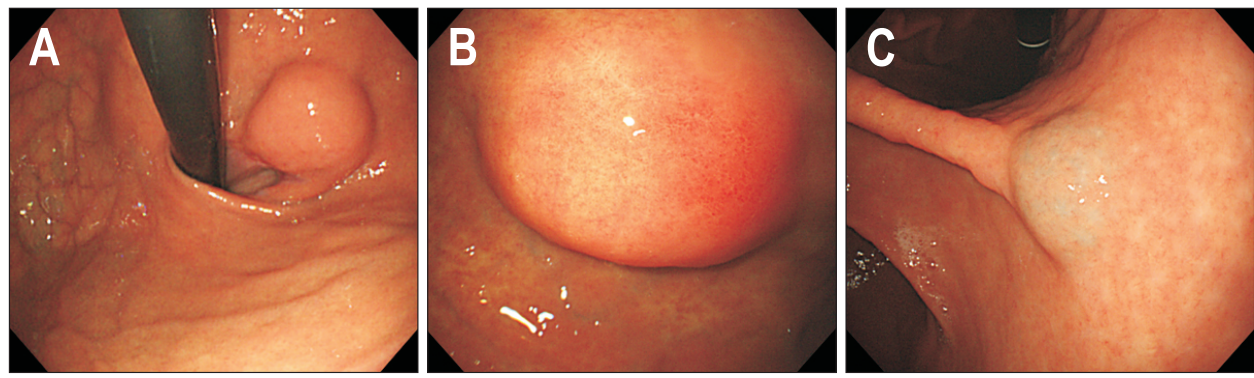

Fig. 2. Macroscopic type of subepithelial tumor according to the Yamada classification. Adapted from Yamada T, et al. Radiology 1974;110:79-83, with permission from Radiological Society of North America. ${ }^{16}$

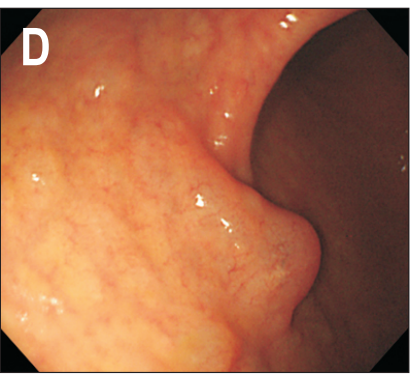

Fig. 3. Color of subepithelial tumors. (A) Normal. (B) Yellowish. (C) Bluish. (D) Translucent. 

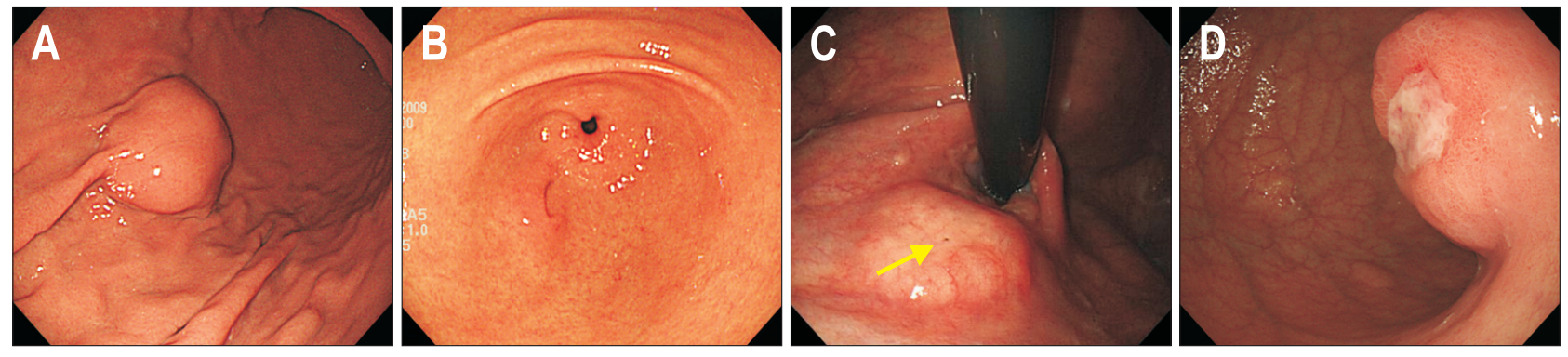

Fig. 4. Surface characteristics of subepithelial tumors. (A) Smooth. (B) Umbilication. (C) Opening lyellow arrow). (D) Ulceration.
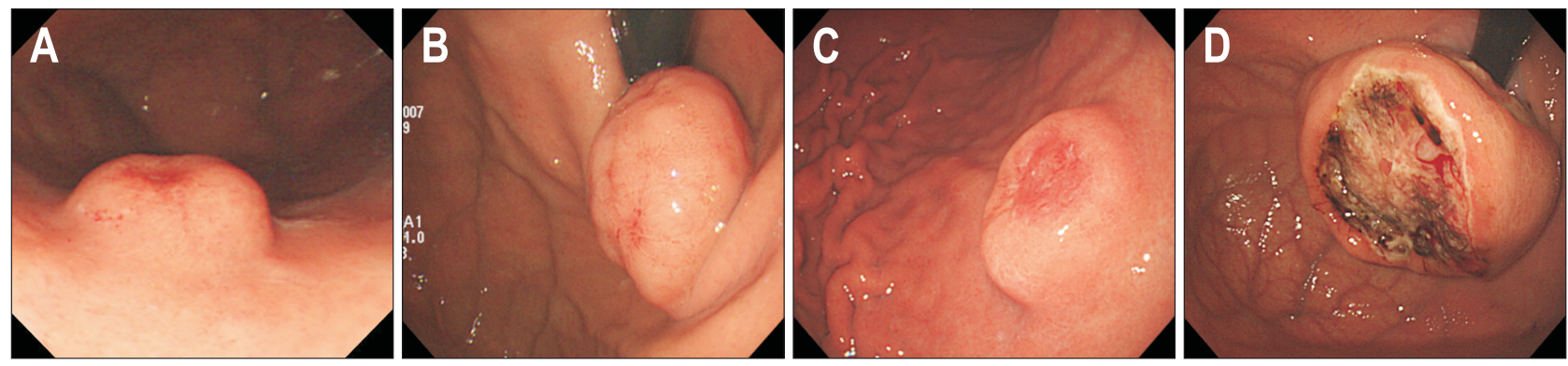

Fig. 5. Representative cases showing surface characteristics indicating malignant potential. (A) Neuroendocrine tumor. (B) Mucosa-associated lymphoid tissue lymphoma. (C) Subepithelial tumor-like carcinoma. (D) Gastrointestinal stromal tumor.

on the surface of SETs using magnifying endoscopy aids in diagnosing ectopic pancreas. ${ }^{20} \mathrm{~A}$ small opening can be sometimes observed in gastritis cystica profunda (Fig. 4C). When an SET presents with erosion or ulceration, the possibility of the SET being malignant lesion increases (Fig. $4 \mathrm{D})$. These surface changes are usually noted in neuroendocrine tumors (NETs), SET-like carcinomas, and GISTs with a high risk of malignant potential (Fig. 5); however, these changes are also observed in IFPs. Therefore, in this situation, multiple and bite-on-bite biopsies should be performed to confirm the tumor histopathology.

\section{Movability}

By pushing an SET from one side to the other using endoscopic biopsy forceps, the endoscopists can evaluate the mobility of the SET. When the tumor is easily movable, the rolling sign is present (Fig. 6) ${ }^{21}$ The clinical implication of the rolling sign is that the SET is located in the muscularis mucosa or deeper layer. Therefore, SETs with components in the lamina propria, such as IFPs, NETs, granular cell tumors, or SET-like carcinomas, do not show the rolling sign. SETs with ulceration, fibrosis, or wide attachment to the muscularis propria also do not show this sign.

The tenting sign has a clinical implication similar to that of the rolling sign. If the overlying epithelium of an SET is easily separated from the tumor itself when the tumor surface is picked up using biopsy forceps, the tenting sign is considered to be present (Fig. 7). The presence of the tenting sign also suggests that the SET is located in the muscularis mucosa or deeper layer. Similarly, SETs with ulceration or fibrosis do not show the tenting sign, irrespective of the layer in which they originate.

\section{Consistency}

By compressing the center of an SET using biopsy forceps, the endoscopists can evaluate the consistency of the SET. When the tumor is easily transformable, it is considered that the pillow sign is present (Fig. 6). ${ }^{22}$ The pillow sign is sometimes called the cushion sign. The clinical implication of the pillow sign is that the SET has a liquid, lipid, or rarely gaseous component. Therefore, this sign is observed in gastritis cystica profunda, duplication cysts, lymphangiomas, and lipomas. However, a prospective study that compared the usefulness of endoscopy and EUS in gastrointestinal subepithelial masses reported that the pillow sign had $98 \%$ specificity, but only $40 \%$ sensitivity for identification of lipomas. ${ }^{22}$ Despite of this limitation, the presence of the pillow sign strongly suggests that the SET is benign. Pushing or compressing the SET strongly using biopsy forceps is contraindicated for SETs with a bluish color, such as varices or hemangiomas, owing to the bleeding risk.

\section{Size}

Because the size of an SET looks different according to the distance and angle between the lesion and the scope, 

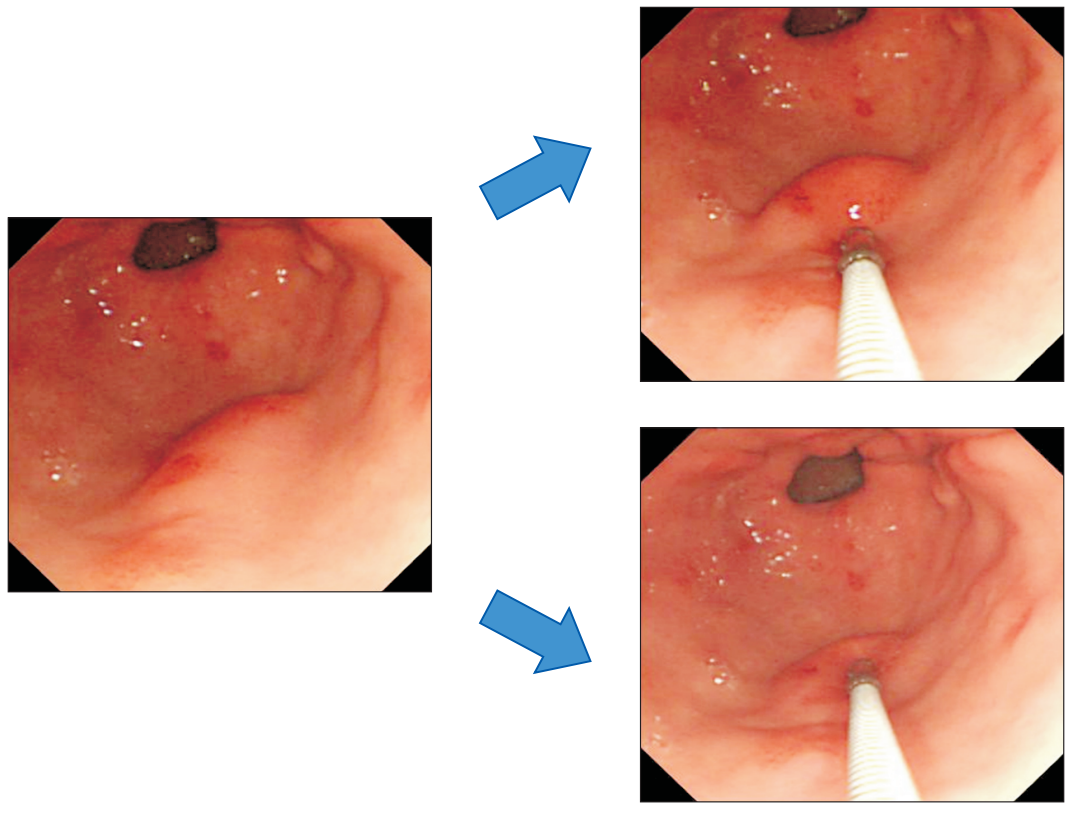

Pillow sign

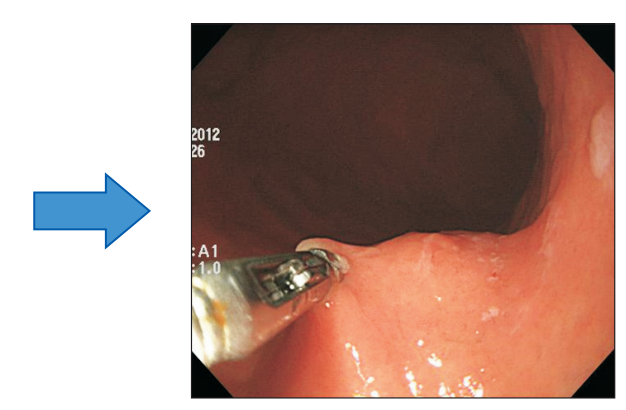

Tenting sign

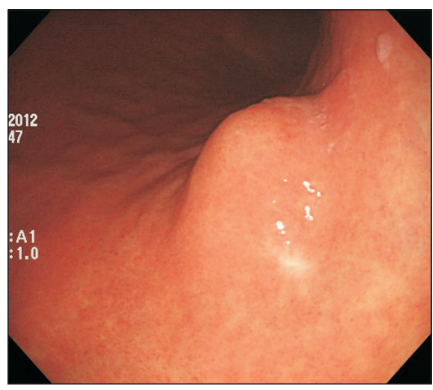

Fig. 7. Tenting sign. When the tumor surface is picked up using biopsy forceps, the overlying epithelium of the subepithelial tumor easily separates from the tumor itself.
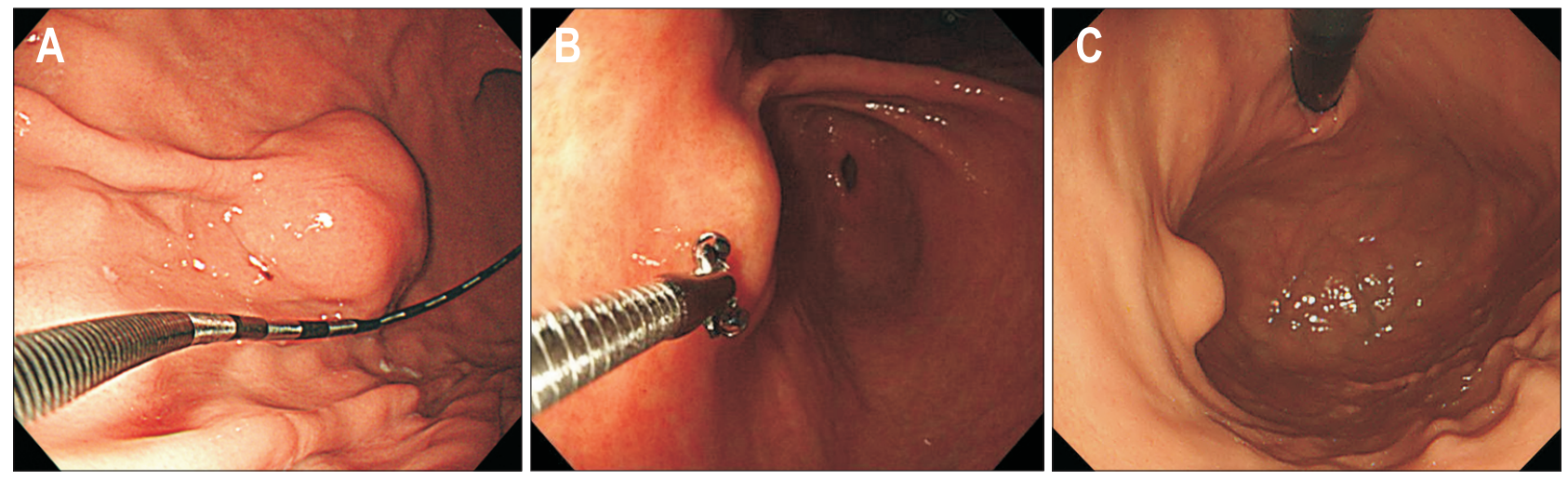

Fig. 8. Measurement of the size of subepithelial tumors. (A) Using an endoscopic square. (B) Using biopsy forceps. (C) Using an endoscope.

it is difficult to measure the size accurately. Therefore, it is important to measure the size objectively using an endoscope ruler or biopsy forceps (Fig. 8A and B). Sometimes, it is useful to estimate the size of an SET in comparison to the diameter of an endoscope in the retroflexed position (Fig. $8 C)$. In a prospective study including 100 gastrointestinal subepithelial lesions, there was a strong correlation between size measurement by endoscopy and that by EUS in intra- mural SETs $(\mathrm{r}=0.88){ }^{22}$ This suggests that when an SET is confirmed to be intramural on endoscopy or EUS, the size of the tumor can be determined using endoscopy alone.

Recent guidelines recommend follow-up using endoscopy or EUS once or twice a year for gastric mesenchymal tumors $<2 \mathrm{~cm}$ in size until they are symptomatic or grow in size. In contrast, surgical resection is recommended for gastric mesenchymal tumors $>5 \mathrm{~cm}$ in size. ${ }^{19,23}$ In cases of 

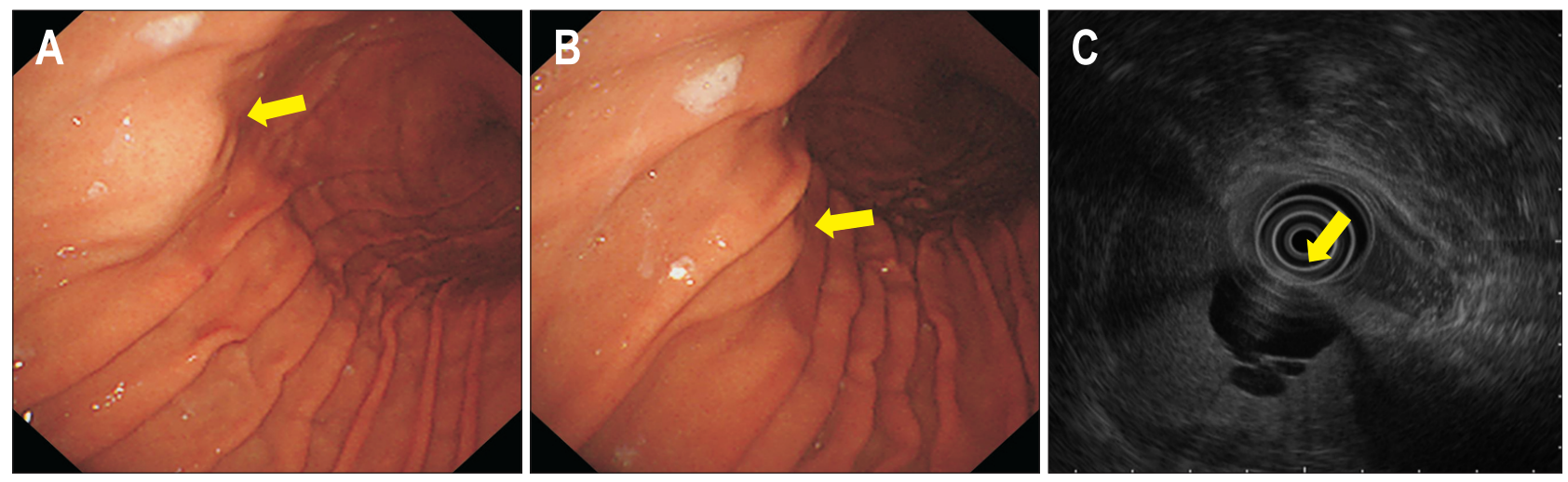

Fig. 9. A case of extraluminal compression. (A) A subepithelial tumor-like lesion is seen in the anterior wall of the midbody (yellow arrow). (B) After slight air deflation, the location and appearance of the lesion change (yellow arrow). (C) Endoscopic ultrasonography shows extraluminal compression by a hepatic cyst (yellow arrow).

gastric mesenchymal tumors 2 to $5 \mathrm{~cm}$ in size, invasive procedures, such as EUS-guided or mucosal cutting biopsy, are generally recommended for histopathologic confirmation. Therefore, exact measurement of the size of SETs is important for deciding the treatment policy. It is also useful to predict the malignant potential of SETs to check their size serially. When the size of an SET is similar or decreases in the follow-up endoscopy 6 to 12 months later, the tumor may be benign. ${ }^{4,24}$ On the contrary, when the size of an SET increases rapidly in the follow-up endoscopy, the malignant potential increases. ${ }^{4}$

\section{WHEN SHOULD ENDOSCOPIC BIOPSY BE PERFORMED?}

In many SET cases, tissue acquisition for histopathologic diagnosis is often necessary to decide further treatment policy. As SETs are covered by the normal mucosa, it is difficult to obtain adequate tissue samples using conventional endoscopic biopsy techniques. Therefore, a bite-on-bite technique (obtaining multiple biopsy specimens on the same site), sometimes by using large-bore forceps, is helpful for obtaining adequate tissue samples. ${ }^{25}$ However, there are several limitations, such as the need for at least 4 to 10 biopsies, an increased bleeding risk (2.8\%), and an unsatisfactory diagnosis yield of $17 \%$ to $42 \%{ }^{25-27}$ Therefore, it is not recommended to perform endoscopic biopsies for all SETs. Endoscopic biopsies using a bite-on-bite technique are useful for SETs without the rolling sign or tenting sign (e.g., NETs, IFPs, SET-like carcinomas, or lymphomas), with large openings (e.g., ectopic pancreas or gastritis cystica profunda), and with erosion or ulceration (GISTs, SET-like carcinomas, or metastatic cancers).

\section{OTHER CLINICAL CLUES USEFUL FOR PREDICTING THE DIAGNOSIS OF SETS}

Besides endoscopic features, other clinical information sometimes provides a clue for predicting the diagnosis of SETs. When an SET is observed in young individuals during the first endoscopy of their life, the possibility that the SET is an ectopic pancreas increases. ${ }^{28}$ When it is observed at the body in middle-aged women, the SET can be diagnosed as leiomyoma, sometimes schwannoma. ${ }^{10,11}$ When it is observed at the body and fundus in old individuals, its possibility of being GIST increases. ${ }^{29}$ According to previous studies, the median age of patients with a GIST is 63 to 69 years, and that of those with a leiomyoma and schwannoma is 52 to 54 years. ${ }^{10,11,23,29}$ When a new SET appears in the non-atrophic mucosa in regions where raw fishes are widely consumed, especially in Far East Asia, the SET can be diagnosed as an eosinophilic abscess or granuloma caused by anisakiasis. ${ }^{24,30}$ Similar to other medical diseases, clinical information can be helpful in predicting the diagnosis of SETs; for example, an SET located in the gastric cardia or fundus of a patient with liver cirrhosis or splenic vein thrombosis is highly indicative of varices, and an SET in the gastric fundus of a patient who has a history of splenectomy or splenic injury is highly suggestive of splenosis.

\section{LIMITATION OF ENDOSCOPY}

As aforementioned, systematic endoscopy for gastric SETs is helpful for the diagnosis and clinical decision, such as follow-up or resection. However, SETs located in the submucosa or muscularis propria, especially those showing an exophytic growth pattern, cannot be diagnosed by endoscopy alone. Even though EUS is performed, the ac- 
curacy of EUS for hypoechoic lesions in the submucosa or muscularis propria is only $50 \%$ to $60 \%{ }^{31}$ In many cases, endoscopy alone can differentiate an SET from extraluminal compression in detailed examination. An alteration in the appearance and location of the lesion according to the change in position of the patient, air insufflation, and respiration and presence of pulsation is useful in predicting whether the lesion is caused by extrinsic compression (Fig. 9). Common causes of extraluminal compression are normal abdominal structures, such as the spleen, splenic vessels, gallbladder, colon, and pancreas. In addition, pathologic lesions such as tumor, cyst, and enlarged lymph node can appear as an SET on endoscopy, especially when the lesion is located in the anterior wall of the gastric body. ${ }^{32}$ However, the sensitivity and specificity of endoscopy to correctly differentiate an SET from extraluminal compression are reported to be $87 \%$ to $98 \%$ and $29 \%$ to $64 \%$, respectively. ${ }^{22,33}$ In addition, although endoscopy indicates that the lesion is an extraluminal compression rather than a true SET, it does not provide information about the cause of extraluminal compression. In this situation, EUS or abdominal computed tomography is needed.

\section{CONCLUSIONS}

Gastric SETs are commonly found during endoscopy. Because most SETs are benign, endoscopists do not worry about these tumors too much. However, endoscopists should not miss SETs with malignant potential, such as GISTs, NETs, lymphomas, SET-like carcinomas, and metastatic cancers. Although advanced diagnostic modalities have been developed, these are not available in all clinics. Considering that conventional endoscopy is the basis and starting point of detecting SETs, it is also important to develop the ability to diagnose SETs based on their endoscopic features and to perform endoscopic biopsies appropriately with a rationale. The systematic endoscopic approach to gastric SETs is summarized in Fig. 10. Furthermore, regular follow-up endoscopy can be an effective surveillance strategy for small $(<2 \mathrm{~cm})$ gastric SETs. ${ }^{23,34}$ During follow-up endoscopy, endoscopists should prudently check for change in the size and surface characteristics of SETs, such as appearance of redness, erosion, or ulceration, taking care not to miss SETs with malignant potential.

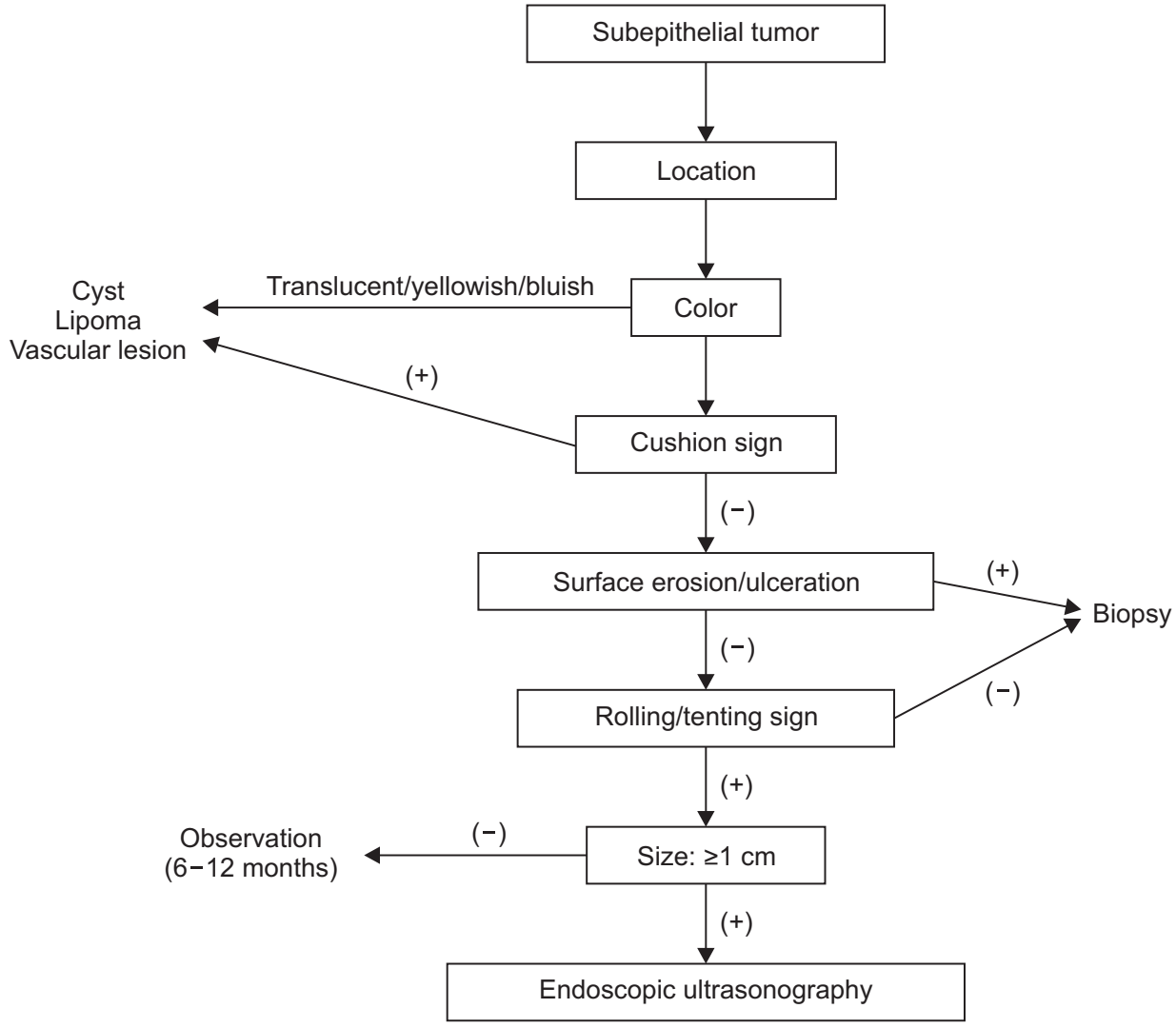

Fig. 10. Systematic endoscopic approach for the diagnosis of gastric subepithelial tumors. 


\section{CONFLICTS OF INTEREST}

G.H.K. is an editorial board member of the Journal but was not involved in the peer reviewer selection, evaluation, or decision process of this article. No other potential conflicts of interest relevant to this article were reported.

\section{ORCID}

Gwang Ha Kim https://orcid.org/0000-0001-9721-5734

\section{REFERENCES}

1. Choe Y, Cho YK, Kim GH, et al. The prevalence, natural course, and clinical practice of upper gastrointestinal subepithelial tumors in Korea. Gastrointest Endosc 2020;91(6 Suppl):AB321.

2. Song JH, Kim SG, Chung SJ, Kang HY, Yang SY, Kim YS. Risk of progression for incidental small subepithelial tumors in the upper gastrointestinal tract. Endoscopy 2015;47:675679.

3. Polkowski M. Endoscopic ultrasound and endoscopic ultrasound-guided fine-needle biopsy for the diagnosis of malignant submucosal tumors. Endoscopy 2005;37:635-645.

4. Kim MY, Jung HY, Choi KD, et al. Natural history of asymptomatic small gastric subepithelial tumors. J Clin Gastroenterol 2011;45:330-336.

5. Kim DH, Kim GH, Cho CM, et al. Feasibility of a 20-gauge ProCore needle in EUS-guided subepithelial tumor sampling: a prospective multicenter study. BMC Gastroenterol 2018;18:151.

6. Kim GH, Cho YK, Kim EY, et al. Comparison of 22-gauge aspiration needle with 22-gauge biopsy needle in endoscopic ultrasonography-guided subepithelial tumor sampling. Scand J Gastroenterol 2014;49:347-354.

7. Nakano Y, Takao T, Morita Y, et al. Reasons for diagnostic failure in forty-five consecutive mucosal cutting biopsy examinations of gastric subepithelial tumors. Clin Endosc 2020;53:575-582.

8. Lee HL, Kwon OW, Lee KN, et al. Endoscopic histologic diagnosis of gastric GI submucosal tumors via the endoscopic submucosal dissection technique. Gastrointest Endosc 2011;74:693-695.

9. Kim SY, Shim KN, Lee JH, et al. Comparison of the diagnostic ability of endoscopic ultrasonography and abdominopelvic computed tomography in the diagnosis of gastric subepithelial tumors. Clin Endosc 2019;52:565-573.

10. Kim GH, Park DY, Kim S, et al. Is it possible to differentiate gastric GISTs from gastric leiomyomas by EUS? World J
Gastroenterol 2009;15:3376-3381.

11. Yoon JM, Kim GH, Park DY, et al. Endosonographic features of gastric schwannoma: a single center experience. Clin Endosc 2016;49:548-554.

12. Park SH, Kim GH, Park DY, et al. Endosonographic findings of gastric ectopic pancreas: a single center experience. J Gastroenterol Hepatol 2011;26:1441-1446.

13. Lee KJ, Kim GH, Park DY, et al. Endoscopic resection of gastrointestinal lipomas: a single-center experience. Surg Endosc 2014;28:185-192.

14. Liu TC, Lin MT, Montgomery EA, Singhi AD. Inflammatory fibroid polyps of the gastrointestinal tract: spectrum of clinical, morphologic, and immunohistochemistry features. Am J Surg Pathol 2013;37:586-592.

15. Baek YH, Choi SR, Lee BE, Kim GH. Gastric glomus tumor: analysis of endosonographic characteristics and computed tomographic findings. Dig Endosc 2013;25:80-83.

16. Yamada T, Ichikawa H. X-ray diagnosis of elevated lesions of the stomach. Radiology 1974;110:79-83.

17. Kim TW, Kim GH, Park DY, et al. Endoscopic resection for duodenal subepithelial tumors: a single-center experience. Surg Endosc 2017;31:1936-1946.

18. Kahng DH, Kim GH, Park DY, et al. Endoscopic resection of granular cell tumors in the gastrointestinal tract: a single center experience. Surg Endosc 2013;27:3228-3236.

19. Hwang JH, Rulyak SD, Kimmey MB; American Gastroenterological Association Institute. American Gastroenterological Association Institute technical review on the management of gastric subepithelial masses. Gastroenterology 2006;130:2217-2228.

20. Oh H, Kim GH, Lee MW, Jeon HK, Baek DH, Lee BE. Magnifying endoscopy with narrow-band imaging for gastric heterotopic pancreas. Endosc Int Open 2018;6:E369-E375.

21. Chun SY, Kim KO, Park DS, et al. Endoscopic submucosal dissection as a treatment for gastric subepithelial tumors that originate from the muscularis propria layer: a preliminary analysis of appropriate indications. Surg Endosc 2013;27:3271-3279.

22. Hwang JH, Saunders MD, Rulyak SJ, Shaw S, Nietsch H, Kimmey MB. A prospective study comparing endoscopy and EUS in the evaluation of GI subepithelial masses. Gastrointest Endosc 2005;62:202-208.

23. Nishida T, Blay JY, Hirota S, Kitagawa Y, Kang YK. The standard diagnosis, treatment, and follow-up of gastrointestinal stromal tumors based on guidelines. Gastric Cancer 2016;19:3-14.

24. Park EY, Baek DH, Kim GH, Lee BE, Lee SJ, Park DY. Endosonographic findings and the natural course of chronic gastric anisakiasis: a single-center experience. Gastroenterol Res Pract 2018;2018:8562792.

25. Ji JS, Lee BI, Choi KY, et al. Diagnostic yield of tissue sam- 
pling using a bite-on-bite technique for incidental subepithelial lesions. Korean J Intern Med 2009;24:101-105.

26. Cantor MJ, Davila RE, Faigel DO. Yield of tissue sampling for subepithelial lesions evaluated by EUS: a comparison between forceps biopsies and endoscopic submucosal resection. Gastrointest Endosc 2006;64:29-34.

27. Hunt GC, Smith PP, Faigel DO. Yield of tissue sampling for submucosal lesions evaluated by EUS. Gastrointest Endosc 2003;57:68-72.

28. Ryu DY, Kim GH, Park DY, et al. Endoscopic removal of gastric ectopic pancreas: an initial experience with endoscopic submucosal dissection. World J Gastroenterol 2010;16:45894593.

29. Lee MW, Kim GH, Kim KB, et al. Digital image analysisbased scoring system for endoscopic ultrasonography is useful in predicting gastrointestinal stromal tumors. Gastric Cancer 2019;22:980-987.

30. Shimamura Y, Honda H, Fukuda K. Is there a link between clinical manifestation of gastric anisakiasis and Helicobacter pylori infection? Clin Endosc 2017;50:510.

31. Humphris JL, Jones DB. Subepithelial mass lesions in the upper gastrointestinal tract. J Gastroenterol Hepatol 2008;23:556-566.

32. Kim YW, Kim GH, Kim DU, et al. The clinical significance of extraluminal compressions according to the site of the stomach. Korean J Gastrointest Endosc 2009;39:125-130.

33. Rösch T, Kapfer B, Will U, et al. Endoscopic ultrasonography. Accuracy of endoscopic ultrasonography in upper gastrointestinal submucosal lesions: a prospective multicenter study. Scand J Gastroenterol 2002;37:856-862.

34. National Comprehensive Cancer Network. NCCN clinical practice guidelines in oncology: gastrointestinal stromal tumors (GISTs) [Internet]. Plymouth Meeting: NCCN; c2020 [cited 2020 Dec 4]. Available from: https://www.nccn.org/ professionals/physician_gls/default.aspx. 